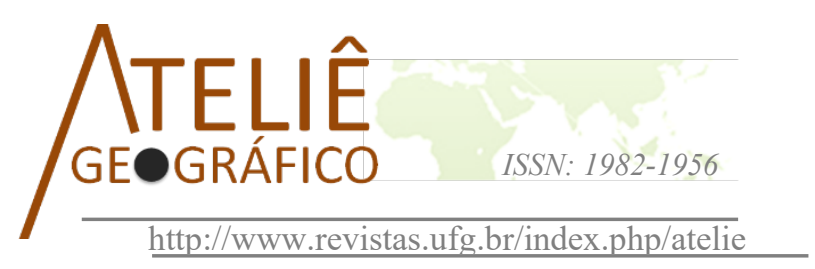

\title{
Presiones por el uso de los comunes urbanos en Áreas Metropolitanas: Caso del humedal Boca Maule en Chile
}

\author{
Pressões para o uso de bens comuns urbanos nas áreas \\ metropolitanas: Caso do pantanal Boca Maule no Chile
}

\section{Use pressure of the urban commons at Metropolitan Areas: Case of "Boca Maule" wetland in Chile}

\author{
Edilia Jaque Castillo \\ Universidad de Concepción \\ edjaque@udec.cl \\ Carolina Ojeda Leal \\ Pontificia Universidad Católica de Chile \\ ccojeda@uc.cl \\ Darío Almendra \\ Universidad de Concepción \\ dalmendra@udec.cl
}

\begin{abstract}
Resumen
Existen dinámicas urbanas favorecidas por un modelo de desarrollo urbano centrado en el mercado, que han presionado en las últimas décadas los ecosistemas naturales de las áreas metropolitanas de Chile, degradando estos comunes urbanos y generando conflictos ambientales. Estudiamos el caso de la cuenca del estero Boca Maule al sur del Área Metropolitana de Concepción (AMC), ciudad de Coronel, la cual presenta patrones de urbanización acelerados a partir de la década de los 90. Esta cuenca alberga un humedal de alto interés ecológico, tanto por su extensión, biodiversidad como por su fragilidad ambiental. Aquí evaluamos los cambios de coberturas de suelo entre 2001 y 2016, mediante clasificación supervisada de imágenes satelitales. Constatamos la reducción de la superficie del humedal, que ha sido reemplazada por urbanización residencial, industrial e infraestructura vial, así como por plantaciones exóticas. Estos procesos desencadenan una agresiva competencia a través del tiempo por los usos entre dos coberturas que producen un efecto de cercamiento (enclosure) entre sí: HumedalSuelo Urbano y Humedal- Forestal.
\end{abstract}

Palabras clave: coberturas de suelo; humedales; comunes urbanos; expansión urbana; Chile. 


\section{Resumo}

Existem dinâmicas urbanas favorecidas por um modelo de desenvolvimento urbano centrado no mercado, que nas últimas décadas pressionou os ecossistemas naturais das áreas metropolitanas do Chile, degradando esses bens comuns urbanos e gerando conflitos ambientais. Estudamos o caso da bacia do estuário de Boca Maule, ao sul da Área Metropolitana de Concepción (AMC), cidade de Coronel, que acelerou os padrões de urbanização a partir da década de 1990. Essa bacia abriga um pântano de alto interesse ecológico, tanto por sua extensão, biodiversidade quanto por sua fragilidade ambiental. Aqui, avaliamos as mudanças na cobertura do solo entre $2001 \mathrm{e}$ 2016, através da classificação supervisionada de imagens de satélite. Podemos ver a redução da superfície do pantanal, que foi substituída por infraestrutura residencial, industrial e rodoviária, além de plantações exóticas. Esses processos desencadeiam uma concorrência agressiva ao longo do tempo pelos usos entre duas coberturas que produzem um efeito de recinto um para o outro: terras úmidas-urbanas e terras úmidasflorestas.

Palavras-chave: cobertura do solo; zonas húmidas; bens comuns urbanos; expansão urbana; Chile
\end{abstract}

\begin{abstract}
There are urban dynamics favored by a market-centered urban development model, which in recent decades have pressed the natural ecosystems of the metropolitan areas of Chile, degrading these urban commons and generating environmental conflicts. We study the case of the Boca Maule estuary basin south of the Metropolitan Area of Concepción (AMC), the city of Coronel, which has accelerated urbanization patterns since the 1990s. This basin houses a wetland of high ecological interest, both for its extension, biodiversity and for its environmental fragility. Here we evaluate the changes in soil cover between 2001 and 2016, through supervised classification of satellite images. We can see the reduction of the surface of the wetland, which has been replaced by residential, industrial and road infrastructure, as well as exotic plantations. These processes trigger aggressive competition over time for the uses between two coverage that produce an enclosure effect on each other: Wetland-Urban Land and Wetland-Forest.
\end{abstract}

Keywords: land use; wetland; urban commons; urban sprawl; Chile.

\title{
Introducción
}

La degradación de los humedales debido a los procesos de urbanización ha aumentado en Chile (CASTRO y FERNÁNDEZ, 2007), en especial en las ciudades costeras del Área Metropolitana de Concepción (AMC) en la región del Biobío (SMITH GUERRA y ROMERO ARAVENA, 2009; ROJAS, et al., 2019). Asociado a la expansión de las ciudades albergadas en su territorio, así también, ligado a procesos industriales impulsados por el Estado, en un principio con el apoyo de CORFO (Corporación de Reconstrucción y Fomento) a partir de la década de 1960 (ALISTE, CONTRERAS y SANDOVAL, 2012), y posteriormente, ligado a las políticas de desarrollo urbano que han contribuido a un crecimiento desordenado y extensivo de esta metrópolis.

Como lo señala Ducci (1998, p.10), las políticas habitacionales chilenas han perpetuado desde entonces un modelo de crecimiento en forma de "mancha de aceite" en donde el crecimiento urbano se da de forma dispersa y los espacios intermedios se van 
llenando de la misma forma como lo hace una gran mancha de aceite al crecer, que tiende a unir las distintas gotas más pequeñas que la rodean fragmentando aun más los pocos espacios naturales circundantes.

Estos procesos de urbanizacion en Chile (PÉREZ y SALINAS, 2007) se han desarrollado de forma descontrolada, muy relacionada a los procesos de mercantilizacion del suelo apoyados por una legislacion laxa que incluye muchas personas/agencias en la toma de decisiones con sus propios intereses, especialmente al momento de llevar a los instrumentos de planificacion territorial estos intereses económicos (HIDALGO, DE MATTOS y ARENAS, 2009). Esto último es relevante, en tanto que serán estos instrumentos los que de cierta forma configuren espacialmente la metropolización ligada al crecimiento urbano.

La superficie urbana en el AMC ha aumentado sostenidamente, pasando de 4.747 ha en 1975 a 9.661 ha en 2004, (ROJAS, PINO y JAQUE, 2013), lo que significó algo más que su duplicación. Asimismo, este crecimiento se presenta de forma dispersa, "segregada y fuertemente relacionada con las condicionantes físicas y ambientales del territorio" (ROJAS, et al., 2006), es decir, un crecimiento que se orienta empujando los límites naturales como cerros, quebradas, riberas de ríos y humedales.

Un caso particular e interesante es el que ofrece la comuna de San Pedro de la Paz en la misma AMC, la cual crece en forma de islas separadas del centro, principalmente con viviendas de altos ingresos localizadas en cerros con vista a los humedales (VÁSQUEZ, et al., 2005), al ser una comuna con gran belleza escénica, se ha convertido en un polo de atracción para proyectos inmobiliarios de alta plusvalía -sector Idahue y Andalué-. El aumento sostenido de superficie urbana, presiona ecosistemas relevantes como humedales, que son comunes urbanos, y han forzado a un cambio en las coberturas de suelo forestales y agrícolas que aportan servicios ambientales, para transformarlas en áreas urbanas (DE LA BARRERA y HENRÍQUEZ, 2017).

Asimismo, Villagrán, et al., (2006) identifican más de veintiuna familias de invertebrados para los humedales de Concepción: Rocuant, Lenga, Los Batros, y Boca Maule. Precisamente estos se encuentran insertos dentro del límite urbano (SEPÚLVEDA, et al., 2012), conviviendo con las actividades y funciones urbanas desreguladas (SMITH GUERRA y ROMERO ARAVENA, 2009)

Así, los humedales, se presentan entonces, como apetecidas áreas de densificación y expansión urbana para las empresas inmobiliarias/industriales y la construcción de carreteras, por lo que es uno de los usos de suelo que más ha perdido superficie en este proceso de expansión del AMC (PAUCHARD, et al., 2006). Estos procesos van aparejados con el crecimiento del metabolismo de las sociedades que consumen cada vez más materiales, energía y agua; impulsan un desplazamiento geográfico de fuentes de recursos y sumideros de residuos hacia la periferia de las grandes urbes (WALTER, 2009), asimismo, pueden desencadenar procesos sociales complejos o determinan la facilidad para el crecimiento urbano (DOUGLAS, 1981; UNU/IAS, 2003). 
Actualmente, sabemos que a medida que los problemas ambientales se vuelven cada vez más evidentes y ubicuos tienden a esparcirse por todos los sectores de la sociedad, independientemente de sus características económicas o de clase (JONES y DUNLAP, 1992), por lo tanto, se ven atravesados por múltiples intereses. Esto nos permite entender que no todos los conceptos que existen en la ecología política, la geografía o la economía, aportan al análisis de todos los conflictos ambientales por la "tensión entre intereses incompatibles con el medio ambiente..." (FOLCHI, 2001).

Los conflictos ambientales para Joan Martínez-Alier (2008) responden a un enfoque clásico, considerando a la naturaleza como un campo en donde se miden fuerzas por el acceso y uso de los recursos; contraponiéndose a las perspectivas transaccionales que ofrece la psicología ambiental (ITTELSON, et al., 1974), en donde se relacionan los seres humanos con los recursos naturales sin un control y a la postura política de Erik Swingedouw (1997) que ha considerado una perspectiva cuantitativa mediada por la influencia económica, es decir, medir quién tiene qué y quién deja de tener acceso a esos recursos (THER, 2006).

Otro autor clásico es Enrique Leff (2003), quien ve procesos de degradación y apropiación de la naturaleza por el ser humano, los cuales generan conflictos de distribución ecológica, coincidiendo con el enfoque de Joan Martínez-Alier, planteando que los costos asociados a este proceso de degradación y apropiación de la naturaleza por el ser humano desembocan en distintos tipos de conflictos ambientales según su motivación:

- Conflictos de distribución ecológica, derivados de la distribución desigual de los recursos ecológicos, los bienes naturales y los servicios ambientales incluyendo movimientos de resistencia al neoliberalismo, de compensación por daños ecológicos y de justicia ambiental.

- Conflictos socioambientales que se plantean en términos de controversias derivadas de formas diversas y muchas veces antagónicas de significación de la naturaleza que está constituida por un conjunto de movimientos sociales y prácticas políticas propias.

- Conflictos de distribución cultural, como los conflictos que emergen de diferentes significados culturales que se abocan a las luchas por la diferencia cultural, las identidades étnicas y las autonomías locales sobre el territorio y los recursos.

Asimismo, otra forma de entender el manejo o aprovechamiento de los recursos naturales es aprehenderlos desde la perspectiva de "la tragedia de los comunes" (HARDIN, 1968; RAMIS, 2013), originaria de Elinor Ostrom (1992) y modernizada por Charlotte Hess (2008), quien ha asociado estos bienes comunes a la creciente urbanización planetaria, que deja obsoleta a los comunes originalmente planteados por Garrett Hardin. Ahora se incluían, por ejemplo, los comunes culturales, los relacionados con los conocimientos digitales, los femeninos (QUIROGA DÍAZ y GAGO, 2014), los de salud o los ecosistemas naturales en la ciudad (SVENDSEN y CAMPBELL, 2008). 
Dada su dualidad, diferenciando entre naturales - artificiales, y materiales inmateriales, estos comunes urbanos se enfrentan a variadas problemáticas que los afectan de acuerdo con lo planteado por Slavoj Žižek (2009), como son: la catástrofe ecológica, el funcionamiento de los regímenes de propiedad privada, los desarrollos tecnocientíficos que los hacen ser apetecidos por el mercado, y las nuevas formas de exclusión de su uso o apartheid.

Dentro de estas problemáticas, las que más complejas son, dada la cantidad de actores que convocan, son aquellas que involucran la gentrificación como degradación y desposesión de recursos comunes (HARVEY, 2004), la fragmentación/ privatización/ securitización de los espacios urbanos, y la colonización del territorio que previamente no estaba ocupado, utilizando el concepto de "cercamiento" (enclosure) para referirse al proceso de neo liberalización de las ciudades.

Asimismo, David Harvey, si bien critica los trabajos de Elinor Ostrom, rescata el papel que ejercen los bienes comunes en la formación de las ciudades y en la política urbana, en donde se ha convertido en una proclama universal "tanto teóricamente como en el campo de la práctica radical en los movimientos sociales urbanos de todo el mundo" (TALLEDOS SÁNCHEZ, 2015). Esto no sólo se centra en lo que se entiende coloquialmente por privatización, es decir, la transferencia de activos públicos al ámbito privado, sino también una multiplicidad y diversidad de actos, que van desde la privatización/financiarización del espacio urbano y la mercantilización de la vida urbana, a la polución, la exclusión, el desplazamiento o el levantamiento material de cercas y muros que restringen el paso o el uso de estos comunes.

Tal como lo reconocen Gago y Mezzadra (2015), las ciudades son objeto de operaciones de extracción, llevadas a cabo mediante la desposesión social de bienes comunes urbanos (en este caso, el particular ecosistema urbano, el ambiente, la diversidad, etc.), a partir de procesos como la gentrificación o densificación habitacional, en donde los efectos trivializantes y homogeneizantes del mercado suponen su agotamiento (CASTRO-COMA Y MARTÍ-COSTA, 2016).

Todo lo anterior ha dado paso a movimientos y luchas de vecinos para "recuperar" el valor de los comunes afectados que van desde movimientos locales de pobladores hasta propuestas teóricas más complejas como la "Democracia de los Comunes" ideada por Hardt y Negri (2000), el influyente "Reclaiming the commons" (2001) de Naomi Klein, o las "Ciudades Rebeldes" de David Harvey (2013). Estas propuestas se enmarcan en dos grandes visiones que aportan desde la teoría y que responden a diferentes causas de estas problemáticas, según plantean Castro-Coma y Martí-Costa (2016) así como Stamm y Aliste (2014):

- La perspectiva neoinstitucionalista, plantea que se deben hacer arreglos institucionales para la gestión de los recursos de uso común (common pool resources) que han sido planteados por Ostrom (1990), Foster (2006; 2011), Hess (2008) y Eizenberg (2012). 
- La perspectiva neomarxista, pone énfasis en lo común, es decir en la distribución de la riqueza planteada por De Angelis (2004), Midnight Notes Collective (1990), Federici (2004), Harvey (2013), Hardt y Negri (2011) y Hodkinson (2012).

Nos centramos en analizar las presiones sobre los comunes urbanos constituidos específicamente por los ecosistemas de humedales en el Área Metropolitana de Concepción (AMC) en la ciudad de Coronel.

La cuenca del Estero Boca Maule (125,5 km2) drena la vertiente occidental de la Cordillera de Nahuelbuta (36 $59^{\circ}$ 'S - $\left.73^{\circ} 11^{\prime} \mathrm{O}\right)$ y alberga esta ciudad minera de 116.262 habitantes (INE 2017) (Fig.1); se trata de un sistema hidrológico relevante y una de las principales fuentes de agua potable que abastece la ciudad. En ella se aloja el humedal denominado Boca Maule que se extiende sobre la llanura de sedimentación fluvio-marina de Lagunillas, sometida a la alternancia de movimientos tectónicos de alzamiento y hundimiento a los cuales debe su génesis (ISLA, et al., 2011:102-103; JAQUE y MANZANARES, 2005). A pesar de su importancia en cuanto a los servicios ecosistémicos que provee, este humedal no se ha estudiado en profundidad.

Nuestra hipótesis es que, al tratarse de una ex ciudad minera, descolgada de los crecimientos económicos y transformada en zona de sacrificio ambiental (BOLADOS, 2016), estos ecosistemas pierden relevancia mediática y ceden ante la presión de un modelo urbano que se expande sin control apoyado en una normativa ambiental y urbana laxa (SUAZO, et al. 2009). En este contexto, el objetivo de este artículo es identificar y relevar los conflictos ambientales presentes en este común urbano, asociados a las dinámicas de usos de suelo y la presión que constituye el modelo de expansión urbana y el modelo forestal sobre el ecosistema humedal, a través del análisis de cambios de uso de suelo y de los actores que interactúan en el conflicto.

\section{Materiales y métodos.}

Proponemos realizar un análisis cuantitativo basado en la interpretación de imágenes satelitales (Landsat L7 y L8 2001, 2016) mediante el método de clasificación supervisada (CHUVIECO, 2000:30-45). Aquí se utilizaron las bandas 5, 6 y 4 para Landsat 7 y 8, usando también ENVI 4.5 (Figura 03), lo cual permitió reconocer ocho categorías de coberturas de suelo: humedal, praderas, suelo urbano, bosque nativo, plantación forestal, cuerpos de agua, matorral y suelos desnudos. 


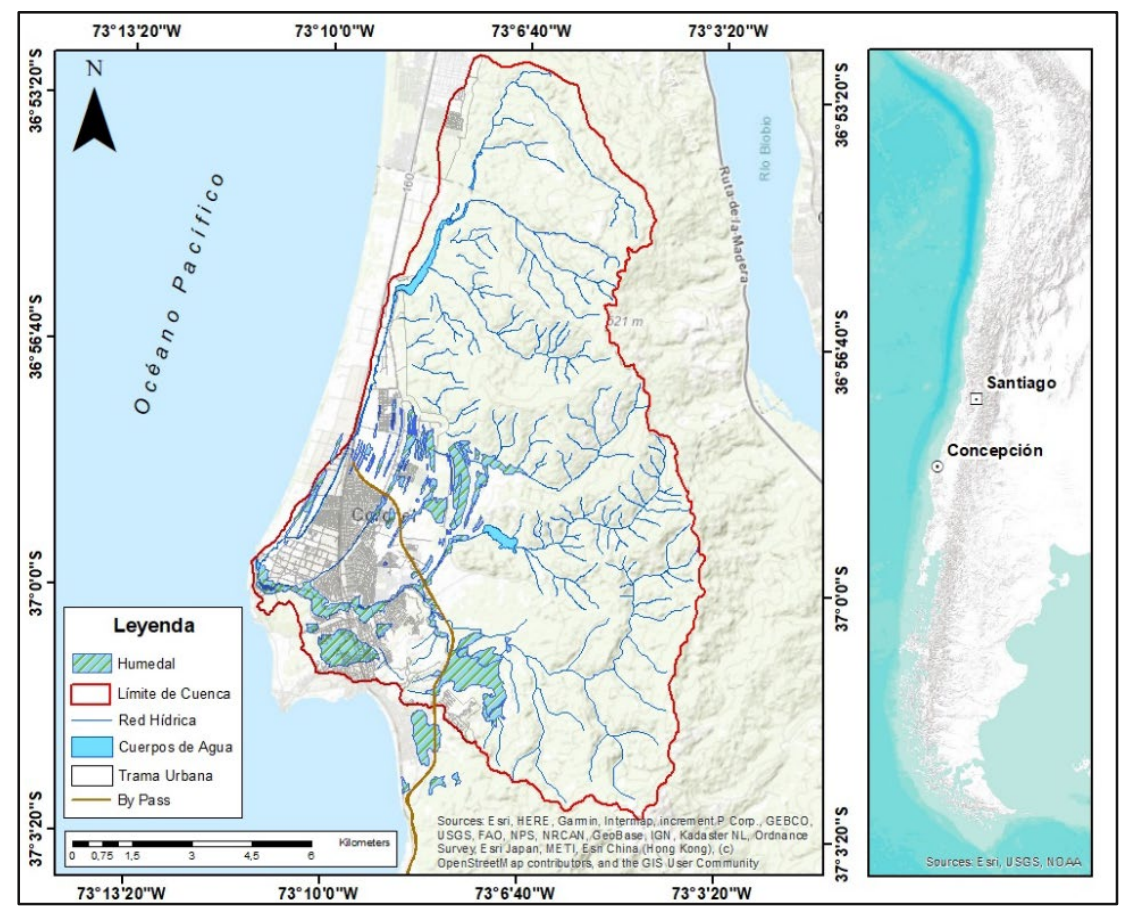

Figura 01: Cuenca del Estero Boca Maule, Región del Biobío - Chile.

Fuente: Elaboración propia a partir de a partir de Mardones et al,1992

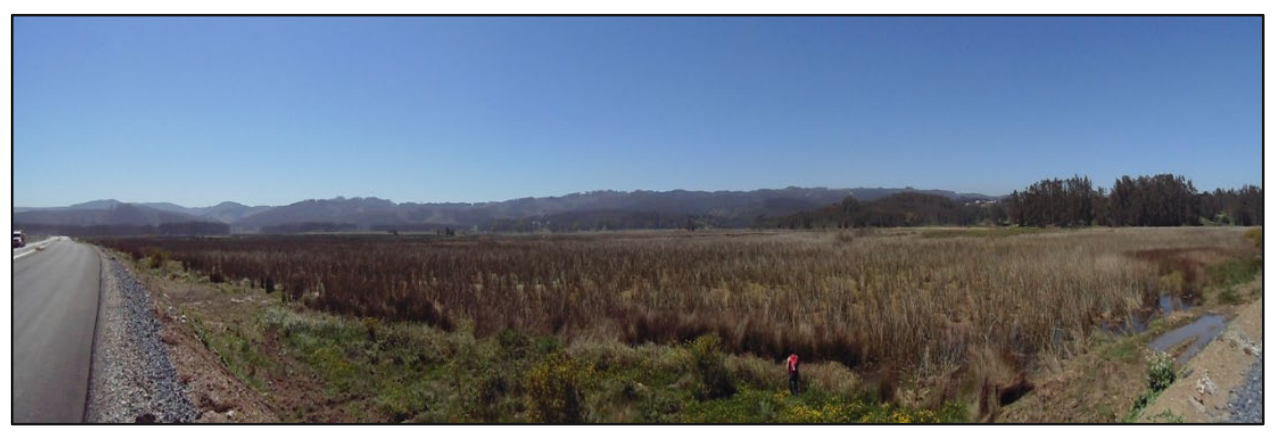

Figura 02: Vista panorámica Humedal Boca Maule, Región del Biobío.

Fuente: Fotografía de las autoras

El trabajo de campo (Figura 02) consistió en la toma de la firma espectral, tomándose 12 puntos de validación por cada categoría $(\mathrm{n}=96)$ abarcando las variaciones espaciales -orientación, pendiente y densidad- (NAVARRO CERRILLO, et al., 2008). Estos puntos se analizaron en una matriz de confusión para comprobar el porcentaje de validez de la clasificación. Además, permitió corroborar la información obtenida por satélites y apreciar la realidad del funcionamiento de este común urbano. Posteriormente 
estas imágenes fueron procesadas y analizadas en el software IDRISI Andes a través del módulo LCM (Land Change Modeler) que permite conocer sus dinámicas espaciotemporales. Esta simulación (1) utiliza los cambios ocurridos para calcular la probabilidad de cambio en un período de tiempo igual al de los cambios iniciales (GARCÍA RUBIO, et al., 2005).

$$
t_{i j}=\frac{\Delta S_{i j}}{n\left(S_{i / t}\right)}
$$

Donde:

$\Delta S_{i j}=$ la diferencia de superficies entre los estados $i$ y $j$;

$n=$ el número total de años del período en estudio; $\mathrm{y}$

$S_{i / t}=$ el área total del estado $i$ a tiempo $t$.

Con estos datos se analizó y discutió la efectiva ocupación del suelo utilizando principalmente las teorías sobre los comunes urbanos, especialmente se intentó visibilizar el fenómeno de cercamiento (enclosure) efectivo en el espacio urbano identificando a los actores que inciden en este proceso, que ahogan a los comunes hasta que pierden completamente sus características funcionales.

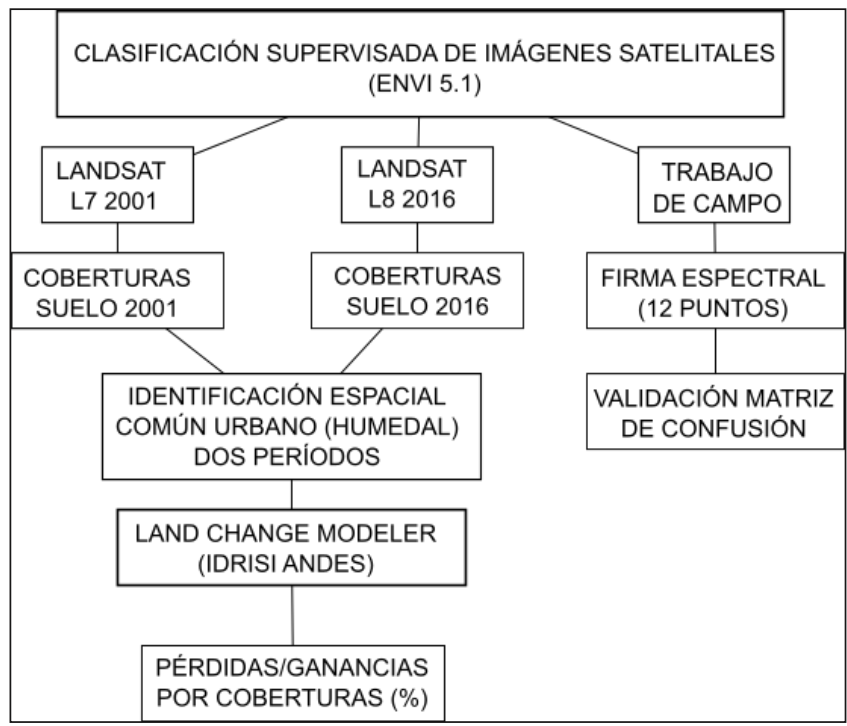

Figura 03: Métodos de trabajo e insumos en GIS.

Elaboración propia

Resultados. El humedal Boca Maule como común urbano inserto en el AMC.

A doce años del cierre de las minas de carbón (ALISTE, et al., 2012; MEZA, 2013), Lota y Coronel continúan liderando las cifras de desempleo nacional (17,4\% y 
15,5\%) cediendo importancia económica ante las comunas de Concepción y San Pedro de la Paz. Producto de su proximidad a Concepción y su potencial industrial/portuario, Coronel registró la mayor superficie total autorizada de edificación de la región (463.875 $\mathrm{m}^{2}$ ), lo cual significó un incremento de 330,3\% respecto al $2010\left(230.102 \mathrm{~m}^{2}\right)$ (MATURANA, et al., 2016). Entre 1992 y 1998, la superficie urbana se incrementó, dando inicio a la ocupación de la planicie litoral de Escuadrón, mediante un crecimiento tentacular por la ruta 160 a Lota, formando parte del parque industrial de Coronel (MARTÍNEZ, et al., 2016).

En este contexto las dinámicas de coberturas de suelo analizadas en la cuenca del Estero Boca Maule muestran que los humedales ocupaban un 0.77\% del total (97,4ha) en el año 2001. En contraste, la mayor cobertura corresponde a las plantaciones forestales con un $48,94 \%$ de la superficie. Cabe destacar que los suelos desnudos y el bosque nativo ocupaban un $5,4 \%$ y $11,96 \%$ de la superficie respectivamente, mientras que la cobertura urbana alcanzaba 5,89\% de la superficie (Figura 04).

Tabla 01: Superficie de las coberturas de suelos de la cuenca del Estero Boca Maule (2001 y 2016).

\begin{tabular}{|c|c|c|c|c|}
\hline \multirow{2}{*}{$\begin{array}{c}\text { Cobertura de suelo / } \\
\text { Años }\end{array}$} & \multicolumn{2}{|c|}{ Año 2001} & \multicolumn{2}{c|}{ Año 2016 } \\
\cline { 2 - 5 } Plantación forestal & 6148.71 & $48.9 \%$ & 8129.01 & $64.7 \%$ \\
\hline Bosque nativo & 1502.77 & $12.0 \%$ & 54.68 & $0.4 \%$ \\
\hline Matorral & 2285.76 & $18.2 \%$ & 420.48 & $3.3 \%$ \\
\hline Cuerpo de agua & 59.57 & $0.5 \%$ & 26.81 & $0.2 \%$ \\
\hline Suelo desnudo & 633.36 & $5.0 \%$ & 196.34 & $1.6 \%$ \\
\hline Humedal cuenca & $\begin{array}{c}\text { Superficie (Ha) } \\
\text { la cuencal de }\end{array}$ \\
\hline Pradera - agrícola & 1098.64 & $8.7 \%$ & 40.18 & $0.3 \%$ \\
\hline Suelo urbano & 741.08 & $5.9 \%$ & 1486.76 & $11.8 \%$ \\
\hline Total & 12567.33 & $100.0 \%$ & 12567.29 & $100.0 \%$ \\
\hline
\end{tabular}

NOTA: La superficie de la cuenca es de $125 \mathrm{~km}^{2}$. Fuente: elaboración propia.

Para el año 2016 la cobertura del humedal disminuye a un 0,31\% (40,18ha), lo cual representa una pérdida de 75,23 ha en relación a la superficie del humedal observada en 2001; esta reducción favorece a los suelos urbanos que se expanden en más del doble de su superficie original (776 ha) (Tabla 01), en donde una parte de esta urbanización se concentra alrededor de la carretera y del estero Boca Maule (Figura 05). Por otro lado, los suelos desnudos y matorrales disminuyen su superficie para dar espacio a praderas, 
mientras que las plantaciones forestales aumentan en desmedro del bosque nativo que disminuye en 1.381,32 ha de su superficie original (Figuras 6-7).

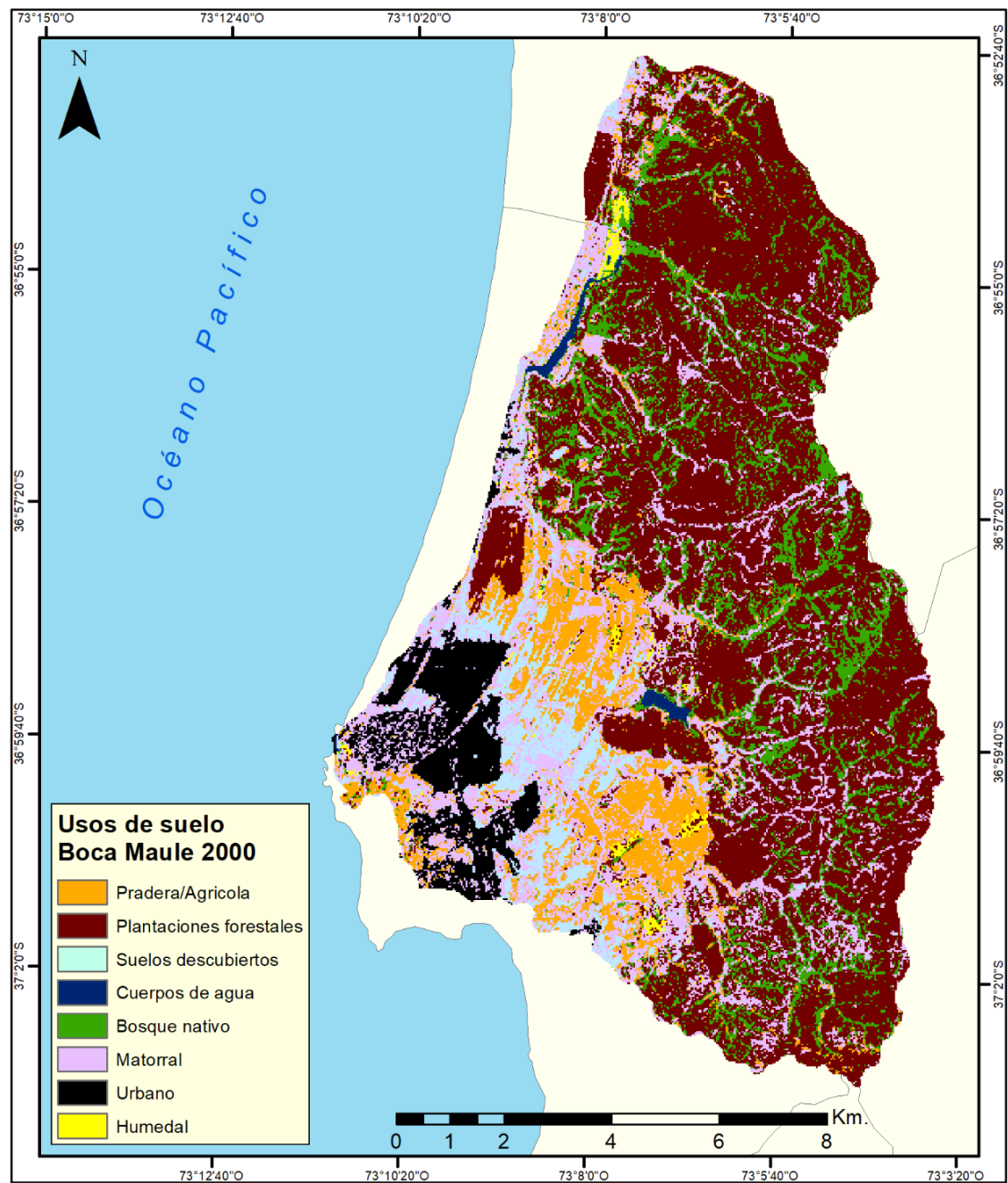

Figura 04: Coberturas de suelo año 2001 Cuenca Estero Boca Maule, Chile.

Fuente: Elaboración propia 


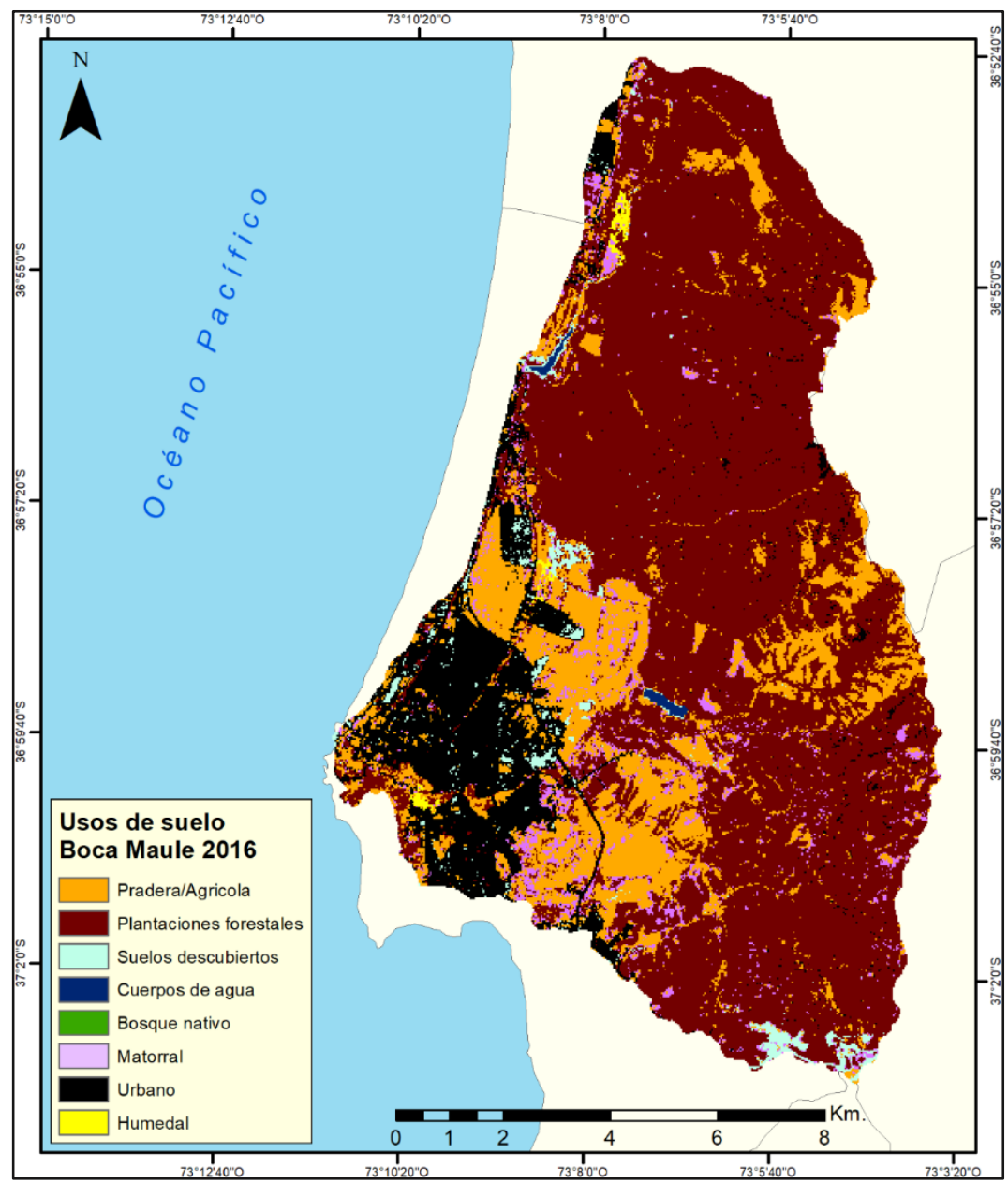

Figura 05: Coberturas de suelo año 2016 Cuenca Estero Boca Maule, Chile Fuente: Elaboración propia. 


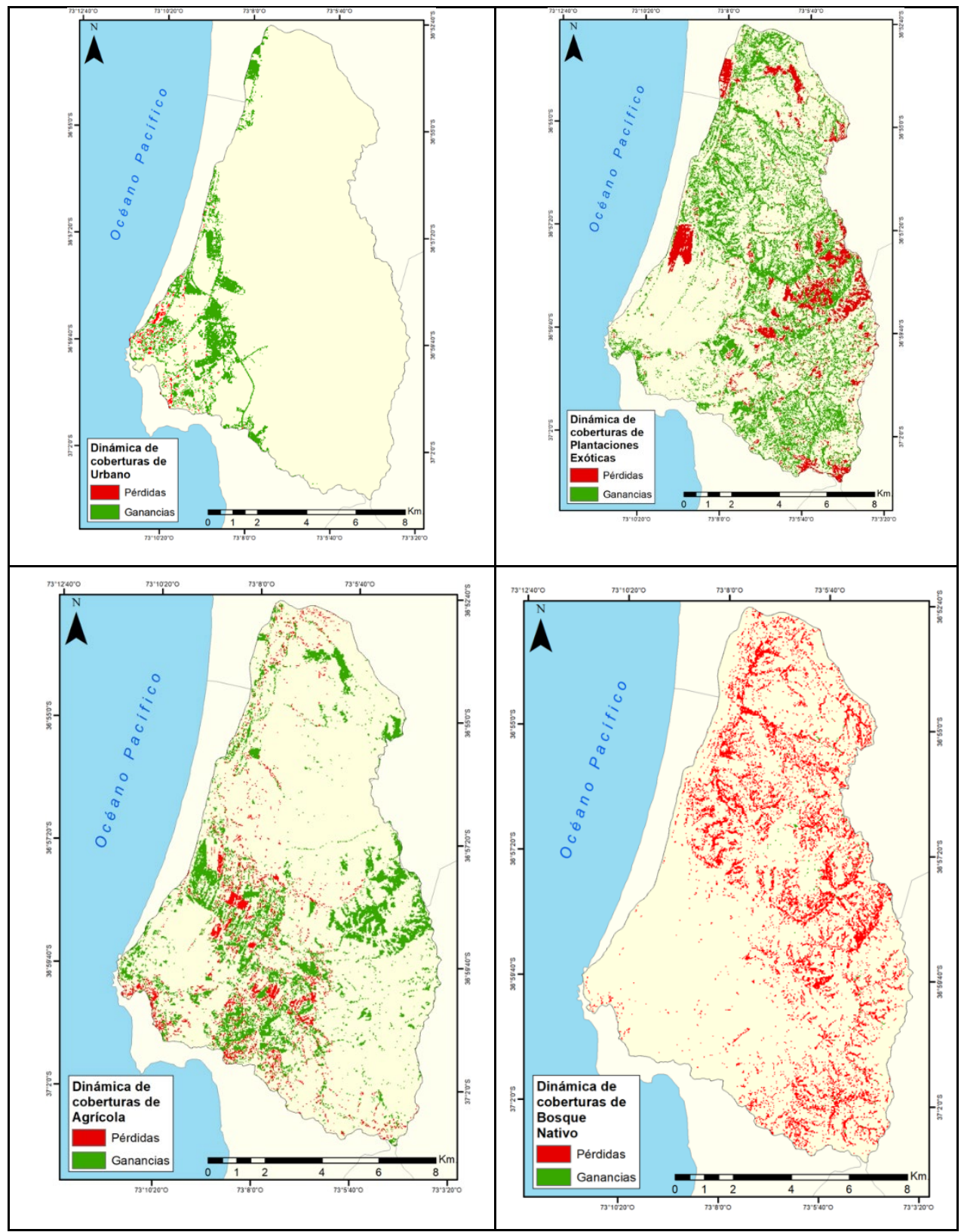

Figura 06: Ganancias, persistencias y pérdidas de las diferentes coberturas de suelo, 2001 - 2016. Cobertura Urbana b) Cobertura Plantaciones exóticas; c) Cobertura agrícola d) Cobertura Bosque Nativo

Fuente: Elaboración propia en IDRISI. 


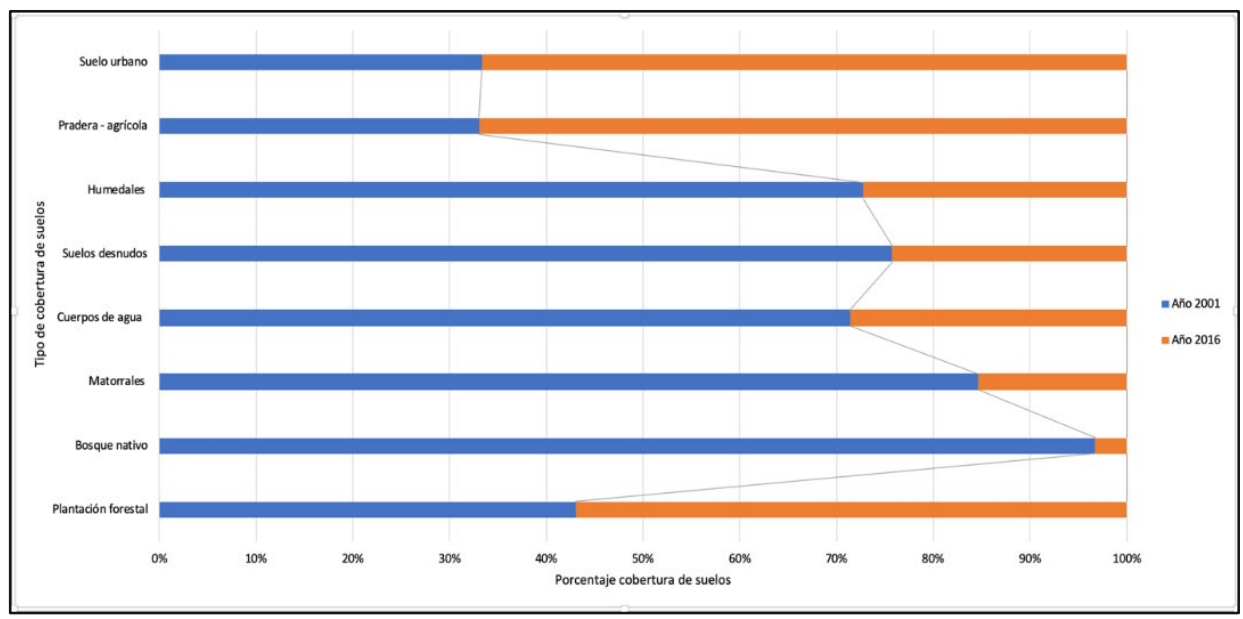

Figura 07: Cambios en las superficies de coberturas de suelo de los años 2001 y 2016 (\%). Fuente: Elaboración propia

\section{Discusión de los resultados: La lenta muerte del humedal Boca Maule: conflictos ambientales por un desarrollo urbano expansivo que presiona a un común urbano.}

De acuerdo con el estudio de Cursach, et al. (2012): "los principales vacíos de información sobre la ecología urbana de las grandes ciudades del sur de Chile tienen relación con la evaluación de los impactos generados sobre los abundantes ecosistemas acuáticos tanto de agua dulce como marinos".

Esta carencia de estudios se extiende a muchos niveles tanto escalares (región, escala de paisajes, comunas, cuencas, ciudades) como niveles transdisciplinares (riesgos socio naturales, servicios ecosistémicos, impactos socioeconómicos, etc.) (CAMPBELL, et al., 2014). Esto muestra la necesidad de entender los grandes desafíos del Antropoceno desde una perspectiva socio ecológica (HAMANN, et al., 2018) teniendo consciencia plena sobre los motivos políticos tras la idea de la naturaleza (SWYNGEDOUW, 2011) y de producción del espacio (SMITH, 2008).

Los estudios que consideran variables ambientales y humanas, son más difíciles y costosos de realizar, por lo que avanzar en estudios de casos que ofrezcan metodologías replicables puede ser muy beneficioso para estudiar comunes urbanos que enfrentan presiones por la ocupación del espacio. Esta presión se expresa espacialmente en las dinámicas de las coberturas de suelo, pero va mucho más allá de lo que se ve a partir de dichas cartografías que sin duda han sido un aporte para su visualización cuantitativa (PRADHAN, 2011; CHUVIECO, 2000). También es una muestra de cómo están las relaciones de desigualdad entre los actores que propician estos cambios en los ecosistemas y vuelve a un tema aparentemente neutro como los recursos naturales o el paisaje (OJEDA LEAL, 2014) en problemas políticos (HUBER, 2019). 
Estas fueron las motivaciones para realizar el estudio de la cuenca del Estero Boca Maule, en la ciudad de Coronel en el sur del AMC. Esta metrópolis presenta patrones de crecimiento y urbanización acelerados a partir de la década de los 90, con usos residenciales e industriales que modificó los paisajes naturales del entorno urbano (SMITH GUERRA y ROMERO ARAVENA, 2009). Esta zona posee una especificidad de biodiversidad que la hace más compleja de preservar (DE LA BARRERA y HENRÍQUEZ, 2017) por estar condicionada por el desarrollo de la industria, el borde costero y la infraestructura vial (PÉREZ y SALINAS, 2007). Este desarrollo se centró en una economía extractiva fundamentada en un modelo neoliberal para generar acumulación de capital en el Norte Global (KRÖGER, 2013; SMITH, 2008), entre ellas: las industrias forestales, celulosa, mineras, agrícolas y termoeléctricas (TORRES, et al., 2015; FALLABELLA y GATICA, 2014).

En este contexto sobrevive un ecosistema de humedal relevante para el AMC, por su extensión y por su fragilidad ambiental, el cual para este análisis se considera como un común urbano. La presión está en los procesos de cercamiento o enclosure que fueron comprimiéndolo a través de: una autopista (bypass Coronel), la urbanización y los basurales urbanos como externalidades de la industria (EL MERCURIO, 2014). Esto disminuye los servicios ecosistémicos que puede ofrecer el humedal como común urbano.

El peso que adquieren las infraestructuras viales y la eliminación de las barreras de distancia para urbanizar no son casos aislados, sino que son formas sistemáticas de construir las ciudades chilenas en donde la naturaleza es vista como un obstáculo.

Esto se aprecia en el caso de la ciudad fluvial de Valdivia y la ciudad costera de Valparaíso, en donde se ha construido "arriba del cerro o sobre el humedal" (HIDALGO et al., 2018). Así también en la reconstrucción del Gran Concepción tras los terremotos de 1939 y 1960 (ALISTE y PEREZ, 2013) en donde la naturaleza es causante de desastres naturales, por lo tanto, las infraestructuras están pensadas para conectar puntos estratégicos del territorio, más que para incluir las dinámicas naturales, como por ejemplo las inundaciones fluviales.

Los principales actores involucrados en este proceso de cercamiento, se obtienen tras la observación de los usos de suelo en la ocupación de la cuenca: la comunidad de Coronel (vecinos/as), las empresas forestales y sus plantaciones, las empresas inmobiliarias e industriales, el Ministerio de Vivienda, el Ministerio de Medio Ambiente y la Municipalidad de Coronel (Figura 08). Estos actores generan presión sobre el humedal, considerándolo como parte de su proyecto e intenciones para con el espacio habitado en desmedro de un manejo participativo de los recursos (BALLET, et al., 2009; GIMÉNEZ, 1999).

Nuestro análisis satelital muestra que la cobertura forestal aumentó en $10,4 \mathrm{~km}^{2}$ entre 2001 y 2016 (Figuras 6-7). Las plantaciones forestales están ubicadas principalmente en la cabecera de la cuenca donde absorben el agua disponible, superficial y subterránea, alterando el patrón de escurrimiento natural de la cuenca. Estas plantaciones forestales 
generan un efecto de desecamiento del humedal, dado el alto consumo de recurso hídrico (HUBER, et al., 2008).

Otros actores que presionan son las empresas inmobiliarias e industriales, que se expresa en el aumento de la cobertura urbana que en 2001 alcanzaba una superficie de $7,41 \mathrm{~km}^{2}$, pasando en 2016 a $14,86 \mathrm{~km}^{2}$. Esto aprovechando las ventajas de una infraestructura vial (bypass a Coronel y los puentes hacia Concepción), que presiona sobre los comunes urbanos y que no posee sentido de adaptación (BERLANT, 2016).

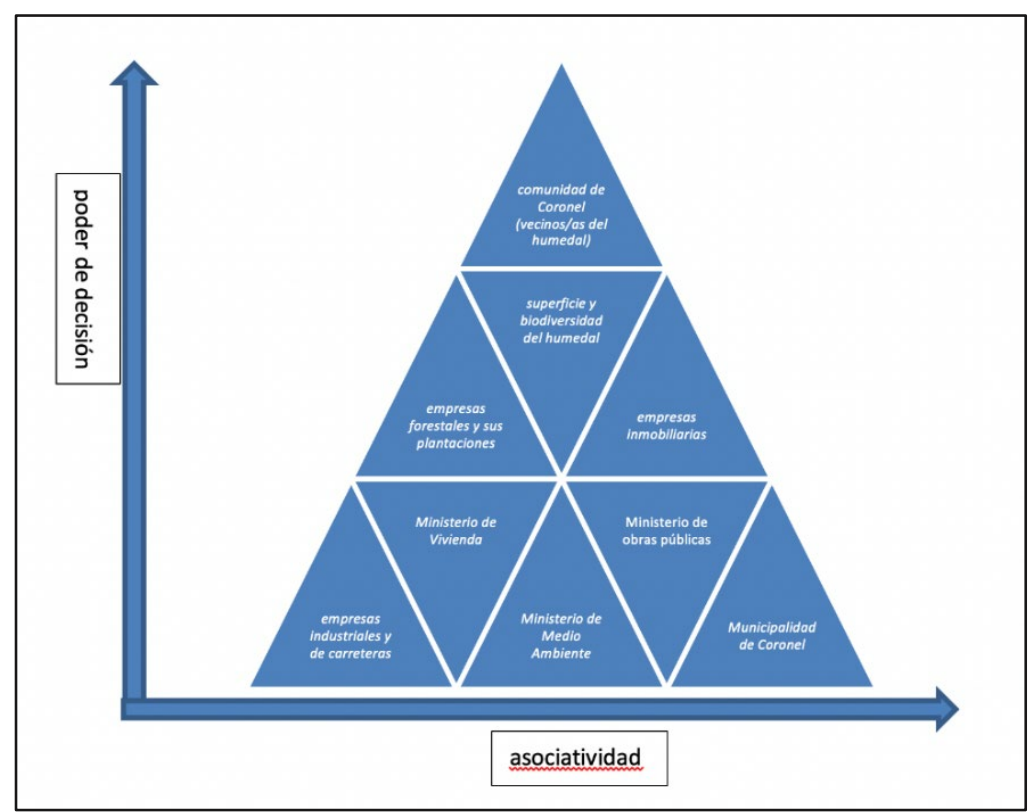

Figura 08: Esquema que representa los actores involucrados que presionan al uso de suelo en el humedal Boca Maule, Chile.

Fuente: Elaboración propia

Por otro lado, la existencia de rellenos ilegales que se han efectuado en el lecho del estero, micro basurales, depósitos de áridos y materiales de escombros no ayudan a la preservación del humedal Boca Maule, evidenciando un desconocimiento de los procesos ecosistémicos (CASTRO LUCIC y FERNÁNDEZ REYES, 2007; SEPÚLVEDA, et al., 2012), permitiendo que se pierdan funciones que benefician a la comunidad completa (MARTÍNEZ POBLETE, 2014). Aumentando también los niveles de vulnerabilidad ante multiamenazas socionaturales en el AMC tales como: inundaciones costeras y fluviales, escasez de agua, olas de calor e incendios forestales (ARAYA-MUÑOZ, et al., 2017).

Como señala Bridgewater, (2011) el agua es permanente fuente de conflictos ambientales, dada las formas centralizadas del poder estatal, y su presencia en los comunes urbanos. Tal es su relevancia que podríamos afirmar con responsabilidad que habitamos una "sociedad hidráulica" (WITTFOGEL, 1957; AKHTER, 2015). Asimismo, el 
concepto de "hidrópolis" de Menga (2017) muestra cómo el agua y la infraestructura son centrales en la construcción de conflictos geopolíticos.

En el caso de Boca Maule estas intervenciones han generado un efecto de resistencia por parte de la comunidad local encabezada por su Municipio, a partir de un "Plan Maestro para la Recuperación del Humedal Boca Maule", desarrollado íntegramente por la Municipalidad de Coronel (SOY CHILE, 2011); el objetivo central de este plan era recuperar e integrar el Humedal al tejido urbano bajo los criterios de la sustentabilidad, sin embargo, aún no es concretado. Actualmente allí se desarrollan actividades de senderismo organizadas por la Fundación Senderos de Chile lo cual beneficia su resguardo a través de la educación ambiental y contemplación paisajística (MARTÍNEZ POBLETE, 2014).

Otra forma de resistencia desde lo institucional fue al actualizar el Plan Regulador Comunal (PRC) para revertir la presión sobre el común urbano y generar un mayor control sobre el mercado de suelo. Este Instrumento de Planificación Territorial (IPT) provee de regulaciones y prohibiciones sobre los permisos de edificación y regula ciertas áreas presentes en la cuenca: Zonas de Riesgo de Inundación por desbordamiento de cauces, la Zona de Conservación Histórica, el Parque Comunal, dos Zonas de Equipamiento de Comercio, Cultura, Deporte, Educación o Esparcimiento y la Zona Residencial mixta.

Al crear el Parque Comunal, se buscó detener el avance urbano y preservar esta zona de alto interés ecológico, con el fin de mejorar la calidad de vida de los habitantes y protegerlos frente a amenazas naturales como inundaciones o tsunamis. Una parte del común se beneficia de esta figura legal, ya que queda inserto en medio de ella, sin embargo, allí se aprecia que un 71,58\% del humedal está destinado a zonas de riesgo por inundación y desborde de cauce -en donde está permitido construir recintos deportivos y parque de entretenciones-, un 6,92 \% corresponde a áreas verdes y, un 1,6\% a zonas de equipamientos diversos.

Finalmente, apreciamos dos grandes conflictos por el uso de este común urbano en el fenómeno del cercamiento en dos grandes coberturas:

- El conflicto Humedal-Urbano, en donde la ausencia de una política de desarrollo urbano vinculante y la falta de la denominación de estos Humedales como Zonas Protegidas, han generado continuos procesos de expansión urbana que se traducen en una disminución de su superficie. Los vecinos no se han concienciado tampoco, con respecto a la importancia de este sector, por lo que continúan haciendo mal uso de este rellenando con áridos y arrojando basura.

- El conflicto Humedal-Forestal genera una configuración espacial que presiona sobre la diversidad de los paisajes naturales, imponiendo monocultivos (pinos y eucaliptos) que fragmentan la diversidad de la región con severos impactos sobre humedales, asociados fundamentalmente a los altos consumos de agua de estas especies. Asimismo, el planeamiento de la infraestructura vial asociada a esta expansión (bypass Coronel) no ha considerado su impacto en las externalidades 
que ha generado, sino que solo se ha preocupado de su finalidad como punto de conexión entre puertos. Esto incluirá a la futura Ruta Piedemonte (DIARIO CONCEPCION, 2018) y el Puente Industrial (DIARIO CONCEPCION, 2019) ambos destinados a fortalecer las funciones de movilidad para la industria forestal y de celulosa.

\section{Conclusiones}

Las presiones por el uso de los comunes urbanos en Áreas Metropolitanas, estudiadas para el humedal Boca Maule en Chile nos permitió concluir que la dinámica de usos del suelo durante el periodo (2001-2016), en la cuenca del estero Boca Maule, dio cuenta de una agresiva competencia en los usos de suelo, donde tres de las coberturas asociadas a ecosistemas naturales considerados "Comunes Urbanos", han perdido superficie. Así es como el humedal es la cobertura de suelo que más pierde superficie pasando de 97,4ha en el año 2001 a 40,18ha en el año 2016; lo mismo ocurre con la cobertura de bosque nativo que pasa de 1.502,77ha en 2001 a 1.381,32 ha en 2016, una disminución que implica más de $11 \%$ de la superficie en estos 15 años; asimismo la cobertura de matorral, también pierde superficie ostensiblemente de 2.285,76 ha en 2001 baja a 420.48 en 2016.

Esto muestra claramente el efecto de cercamiento de los comunes urbanos, presionados por las coberturas antrópicas asociadas al desarrollo urbano y silvícola, potenciadas por modelos económicos de desarrollo urbano y forestal. Así es como las coberturas que mayor crecimiento mostraron son las plantaciones forestales que pasaron de 6.148,71 ha en 2001 a 8.129,01 ha en 2016 cubriendo más del 64\% de la cuenca. Por su parte la cobertura de suelo urbana alcanzaba 741.08 ha en $2001(5,89 \%)$ y en 2016 llega a cubrir $1.486,76$ ha un $11.8 \%$ de la cuenca.

Los conflictos ambientales que surgen entonces, son los denominados conflictos de distribución ecológica y los conflictos socioambientales fundamentados en las presiones que se ejercen entre dos coberturas Humedal-Suelo Urbano y HumedalForestal, estas presiones observadas mantienen a estos actores como los principales competidores por recursos naturales cada vez más escasos como lo son el agua y el suelo, que son utilizados y explotados por las empresas inmobiliarias, y por las industrias y empresas forestales, causando finalmente graves daños a la biodiversidad del humedal, demostrada principalmente en su disminución de superficie.

Por otro lado, surgen también actores locales que generan una acción de resistencia frente a los actores económicos. Se pudo constatar que el instrumento de planificación urbana Plan Regulador Comunal de Coronel, actúa como un actor mixto Estado/ Comunidad, que logra plantear una propuesta de protección de recursos naturales que corresponde a la iniciativa para obtener la Declaración del Humedal Boca Maule como Santuario de la Naturaleza ante el Ministerio de Medio Ambiente, dado su alto valor ambiental dentro del contexto urbano, pero que aun no se resuelve. 
La única medida que se ha llevado a cabo hasta ahora desde este instrumento regulatorio es la de incluir al humedal dentro del Plan Regulador Comunal de Coronel, como Parque Comunal, sin reconocerlo como humedal propiamente tal; por otro lado la comunidad organizada y apoyada por ONG realizan senderos de observación de aves/paisaje concientizando a la población en la valoración de este común urbano.

Por lo tanto no ha existido en Chile una política seria y eficiente que responda frente a estas presiones, sobre los comunes urbanos, que en un contexto de modelo económico liberal potenciado por dos políticas públicas diferentes y eficientes, terminan convergiendo en un contexto territorial al cual presionan y reducen a traves de la forma de ocupación del suelo; el modelo forestal (MFC) por un lado reduciendo los bosques y matorrales nativos y el Modelo de Desarrollo Urbano (MDU) por otro lado, rellenando los humedales, todo ello facilitado por normativas laxas que propician la construcción de un territorio de sacrificio ambiental.

\section{Referencias}

AKHTER, M. Infrastructure nation: State space, hegemony, and hydraulic regionalism in Pakistan. Antipode, vol. 47, no.4, pp. 849-870, 2015. Retrieved from: https://doi.org/10.1111/anti.12152 Accesssed in: 12 August 2018.

ALISTE ALMUNA, E., CONTRERAS ALONSO, M., SANDOVAL MANRÍQUEZ, V. Industrialización, desarrollo y ciudad: transformaciones socio-demográficas y espaciales en la geografía social del gran Concepción (1950-2010). Revista INVI, vol.27, no.75, pp.21-71, 2012. http://dx.doi.org/10.4067/S0718-83582012000200002 Accesado en: 12 agosto 2018.

ALISTE, E; PEREZ, S. La reconstrucción del Gran Concepción: territorio y catástrofe como permanencia histórica. Revista de Geografia Norte Grande, no. 54, p. 199-218, 2013. http://dx.doi.org/10.4067/S0718-34022013000100011. Accedido en 02 dic. 2019.

ARAYA-MUÑOZ, D., METZGER, M.J., STUART, N., MERIWETHER, A., WILSON, W., CARVAJAL, D. A spatial fuzzy logic approach to urban multi-hazard impact assessment in Concepción, Chile. Science of the Total Environment, vol.576, pp.508-519, 2017http://dx.doi.org/10.1016/j.scitotenv.2016.10.077 Accesssed in: 12 May 2019.

BALLET, J., KOUAMÉKAN KOFFI, J.-M., KOMENA, B.K. Co-management of natural resources in developing countries: the importance of context. Économie Internationale, vol.120, pp.53-76, 2009.

BERLANT, L. The Commons: Infrastructures for troubling times. Environment and Planning D: Society and Space, vol. 34, no. 3, pp. 393-419, 2016 doi:10.1177/0263775816645989. Accesssed in: 02 December 2019.

BOLADOS GARCÍA, P. Conflictos socio-ambientales/territoriales y el surgimiento de identidades post neoliberales (Valparaíso-Chile). Izquierdas, no.31, pp.102-129, 2016. https://dx.doi.org/10.4067/S0718-50492016000600102 Accesado en: 12 agosto 2018. 
BRIDGEWATER, P. Water Services in Urban Landscapes. Urban Ecology: Patterns, Processes and Applications. Londres: SAGE, 2011.

CAMPBELL, C.A., LEFROY, E.C., CADDY-RETALIC, S., BAX, N., DOHERTY, P.J., DOUGLAS, M.M., BAXD, N., WEST, J. Designing environmental research for impact. Science of the Total Environment, no.534, pp.4-13, 2015.

https://doi.org/10.1016/j.scitotenv.2014.11.089 Accesssed in: 12 May 2019.

CASTRO-COMA, M., MARTÍ-COSTA, M. Comunes urbanos: de la gestión colectiva al derecho a la ciudad. EURE vol.42, no. 125, pp.131-153, 2016.

http://dx.doi.org/10.4067/S0250-71612016000100006 Accedido en 02 dic. 2019

CASTRO LUCIC, M., FERNÁNDEZ REYES, L. (Eds.) Gestión Sostenible de Humedales. Santiago de Chile: Programa Iberoamericano de Ciencias y Tecnología para el Desarrollo (CYTED), Centro del Agua para Zonas Áridas y Semiáridas de América Latina y el Caribe (CAZALAC), y Programa Internacional de Interculturalidad Universidad de Chile, 2007

CURSACH, J.A., RAU, J.R., TOBAR, C.N., OJEDA, J.A. Estado actual del desarrollo de la ecología urbana en grandes ciudades del sur de Chile. Revista de Geografia Norte Grande, vol.52, pp.57-70, 2012. http://dx.doi.org/10.4067/S0718-34022012000200004 Accesado en: 12 agosto 2018.

CHUVIECO, E. Fundamentos de teledetección espacial. España: Rialp, 2000

DE ANGELIS, M. Separating the doing and the deed: Capital and the continuous character of enclosures. Historical Materialism, vol.12, no.2, pp.57-87, 2004 doi:

10.1163/1569206041551609. Accesssed in: 12 August 2018.

DE LA BARRERA, F., HENRÍQUEZ, C. Vegetation cover change in growing urban agglomerations in Chile. Ecological Indicators, no.81, pp.265-273, 2017.

http://dx.doi.org/10.1016/j.ecolind.2017.05.067 Accesssed in: 12 August 2018.

DIARIO CONCEPCIÓN. "Gobierno compromete acelerar obras de Ruta a Pie de Monte". 26 de Septiembre 2018. Disponible en:

https://www.diarioconcepcion.cl/ciudad/2018/09/26/gobierno-compromete-acelerar-obrasde-ruta-a-pie-de-monte.html Accesado en: 12 octubre 2019.

DIARIO CONCEPCIÓN. "Primera piedra del Puente Industrial sería antes de fin de año". 04 de agosto 2019. Disponible en:

https://www.diarioconcepcion.cl/ciudad/2019/08/04/primera-piedra-del-puente-industrialseria-antes-de-fin-de-ano.html Accesado en: 12 octubre 2019.

DOUGLAS, I. The city as ecosystem. Progress in Physical Geography: Earth and Environment, vol.5, no. 3, pp. 315-367, 1981. https://doi.org/10.1177/030913338100500301 Accesssed in: 18 August 2018.

DUCCI, M.E. Santiago ¿Una mancha de aceite sin fin? ¿Qué pasa con la población cuando la ciudad crece indiscriminadamente? EURE, vol.24, no.72, pp.85-94, 1998.

https://dx.doi.org/10.4067/S0250-71611998007200005 Accesado en: 12 agosto 2018. 
EL MERCURIO. "Municipalidad de Coronel denuncia que vertedero en humedal podría pertenecer a termoeléctrica". Lunes, 07 de marzo de 2014. Disponible en:

https://www.emol.com/noticias/nacional/2014/03/07/648381/vecinos-de-coronel-denuncianque-vertedero-en-humedal-podria-pertenecer-a-termoelectrica.html Accesado en: 12 agosto 2018.

EIZENBERG, E. Actually existing commons: Three moments of space of community gardens in New York City. Antipode, vol.44, no.3, pp.764-782, 2012. doi: 10.1111/j.14678330.2011.00892.x

FALLABELLA, G., GATICA, H. Sector forestal-celulosa, agricultura de secano e industria en el Gran Concepción ¿Encadenamiento productivo o enclave? Revista CEPAL, no.112, pp.197-215, 2014.

FEDERICI, S. Calibán y la bruja: Mujeres, cuerpo y acumulación originaria. Madrid: Traficantes de Sueños, 2004

FIGUEROA, R., SUAREZ, M.L., ANDREU, A., RUIZ, V.H., VIDAL-ABARCA, M. Caracterización Ecológica de Humedales de la Zona Semiárida en Chile Central. Gayana, vol.73, no.1, pp.76-94, 2009. https://dx.doi.org/10.4067/S0717-65382009000100011 Accesado en: 12 agosto 2018.

FOLCHI, M. Conflictos de contenido ambiental y ecologismo de los pobres no siempre pobres, ni siempre ecologistas. Ecología política, no.22, pp.79-100, 2001. Recuperado de https://dialnet.unirioja.es/servlet/articulo?codigo=153467 Accesado en: 12 agosto 2018.

FOSTER, S. R. City as an ecological space: Social capital and urban land use. Notre Dame Law Review, vol.82, no.2, pp.527-582, 2006. Disponible en: http://papers.ssrn.com/sol3/papers.cfm/abstract_id=899617

GAGO, V., MEZZADRA, S. A critique of the extractive operations of capital: toward an expanded concept of extractivism. Rethinking Marxism vol.29, no.4, pp. 574-591, 2017. https://doi.org/10.1080/08935696.2017.1417087 Accessed 02 dic. 2019

GARCÍA RUBIO, G., SCHMOOK, B., ESPEJEL, I. Dinámica en el uso del suelo en tres ejidos cercanos a la ciudad de Chetumal, Quintana Roo. Investigaciones Geográficas, no.58, pp.122-139, 2005. Recuperado de

http://www.scielo.org.mx/scielo.php?script=sci_arttext\&pid=S0188-

$46112005000300008 \& \operatorname{lng}=$ es\&tlng=es Accesado en: 12 agosto 2018.

GIMÉNEZ, G. Territorio, cultura e identidad. Estudios sobre las Culturas Contemporáneas. Época II, vol.5, no.9, pp.25-57, 1999. Disponible en:

http://www.redalyc.org/articulo.oa?id=74702202 Accesado en: 12 agosto 2018.

HAMANN, M., BERRY, K., CHAIGNEAU, T., CURRY, T., HEILMAYR, R., PATRIK, J., HENRIKSSON, G. ... AND WU, T. Inequality and the Biosphere. Annual Review of Environment and Resources, no.43, pp.61-83, 2018. https://doi.org/10.1146/annurevenviron-102017-025949 Accesssed in: 12 septiembre 2018. 
HARDT, M., NEGRI, A. Empire. Cambridge: Harvard University Press, 2000

HARDIN, G. The Tragedy of the Commons. Science, vol. 162, Issue 3.859, pp. 1.243-1.248, 1968. DOI: $10.1126 /$ science. 162.3859 .1243

HARVEY, D. Retrospect on the limits to capital. Antipode, vol. 36, no. 3, pp.544-9, 2004.

HARVEY, D. Ciudades rebeldes. Del derecho de la ciudad a la revolución urbana. Madrid: Akal, 2013.

HESS, C. Mapping the New Commons. Presented at "Governing Shared Resources: Connecting Local Experience to Global Challenges;" the 12th Biennial Conference of the International Association for the Study of the Commons, University of Gloucestershire, Cheltenham, England. July 14-18, 2008. http://dx.doi.org/10.2139/ssrn.1356835 Accedido en 02 dic. 2019

HIDALGO, R., RODRIGUEZ, L., ALVARADO, V. Arriba del cerro o sobre el humedal: producción de naturaleza y expansión inmobiliaria en ciudades marinas y fluviales. El caso de Valparaíso y Valdivia, Chile. Diálogo Andino, no. 56, p. 87-100, 2018. http://dx.doi.org/10.4067/S0719-26812018000200087. Accesado en 02 dic. 2019.

HIDALGO, R., DE MATTOS, C., ARENAS, F. (Eds.) Chile: del país urbano al país metropolitano. Santiago: Instituto de Geografía - Instituto de Estudios Urbanos y Territoriales de la Pontificia Universidad Católica de Chile, 2009. Disponible en:

http://geografia.uc.cl/images/serie_GEOlibros/del_pais_urbano/arenas_hidalgo_Del_pais_ur bano_al_pais_metropolitano.pdf Āccedido en 20 marzo 2020.

HODKINSON, S. The new urban enclosures. City, vol.16, no.5, pp.500-518, 2012. doi: 10.1080/13604813.2012.709403. Accedido en 02 dic. 2019.

HUBER, A., IROUMÉ, A., BATHURST, J. Effect of Pinus radiata plantations on water balance in Chile. Hydrological Processes, vol.22, no.1, pp.142-148, 2008. https://doi.org/10.1002/hyp.6582 Accesssed in: 18 August 2018.

HUBER, M. Resource geography II: What makes resources political? Progress in Human Geography, vol.43, no.3, pp.553-564, 2019. DOI: 10.1177/0309132518768604. Accedido en 02 dic. 2019.

INE, 2017. Censo Nacional de Poblacion. Instituto Nacional de Estadística. Chile.

ISLA, F., QUEZADA, J., MARTÍNEZ, C., FERNÁNDEZ, A., JAQUE, E. The evolution of the Biobío delta and the coastal plains of the Arauco Gulf, Biobío region: the Holocene sealevel curve of Chile. Journal of Coastal Research, vol. 28, no.1, pp.102-111, 2012. http://dx.doi.org/10.2112/JCOASTRES-D-10-00035.1 Accesssed in: 18 August 2018.

ITTELSON, W. H., PROSHANSKY, H. M., RIVLIN, L. G., WINKEL, G. H. An introduction to environmental psychology. New York: Holt, Rinehart \& Winston, 1974.

JAQUE, E., MANZANARES, P. Evaluación de la erodabilidad hídrica en una cuenca hidrográfica lacustre del litoral central (Laguna Quiñenco). Revista de Geografia Norte 
Grande, no.33, pp.103-112, 2005. Disponible en:

http://www.redalyc.org/articulo.oa?id=30003307 Accedido en 02 dic. 2019.

JONES, R., DUNLAP, R. The social bases of environmental concern: Have they changed over time? Rural Sociology, vol.57, no.1, pp.28-47, 1992. https://doi.org/10.1111/j.15490831.1992.tb00455.x Accedido en 02 dic. 2019

KLEIN, N. Reclaiming the Commons. New Left Review, vol. 9, pp. 81-89, 2001. Available at: https://newleftreview.org/issues/II9/articles/naomi-klein-reclaiming-the-commons Accedido en 02 dic. 2019

KRÖGER, M. Globalization as the 'Pulping' of Landscapes: Forestry Capitalism's NorthSouth Territorial Accumulation. Globalizations, vol.10, no.6, pp.837-853, 2013. DOI: $10.1080 / 14747731.2013 .814433$

LEFF, E. La ecología política en América Latina: un campo en construcción. Sociedade e Estado, vol.18, no.1-2, pp.17-40, 2003. https://dx.doi.org/10.1590/S010269922003000100003 Accesado en: 12 agosto 2018.

MARTÍNEZ ALIER, J. Conflictos ecológicos y justicia ambiental. Papeles de relaciones ecosociales y cambio global, no.103, pp.11-27, 2008. Disponible en: http://www.fuhem.es/media/ecosocial/file/Analisis/enero\%202009/Conflictos\%20ecologicos _J.\%20MARTINEZ\%20ALIER.pdf Accesado en: 12 agosto 2018.

MARTÍNEZ, C., ROJAS, C., ROJAS, O., QUEZADA, J., LÓPEZ, P., RUÍZ, V. Crecimiento urbano sobre geoformas costeras de la llanura de San Pedro, Área Metropolitana de Concepción. En: HIDALGO, R. (Ed.). En las Costas del Neoliberalismo. Naturaleza, Urbanización y Producción Inmobiliaria: Experiencias de Chile y Argentina. Santiago: Pontificia Universidad Católica de Chile - Pontificia Universidad Católica de Valparaíso, 2016.

MARTÍNEZ POBLETE, J. Catastro y estado de conservación de los humedales marinos/costeros en la región del Biobío. Revista Tiempo y Espacio, no.33, pp.104-130, 2014. Disponible en: http://revistas.ubiobio.cl/index.php/TYE/issue/view/221 Accesado en: 12 agosto 2018.

MATURANA, F., ROJAS, A., POBLETE, D. Trayectoria, evolución y estructura del sistema de ciudades: el caso de la región del Biobío (Chile). Cuadernos de Geografía, vol.25, no.2, pp.39-58, 2016. https://dx.doi.org/10.15446/rcdg.v25n2.45787 Accesado en: 12 agosto 2018.

MENGA, F. Hydropolis: Reinterpreting the polis in water politics. Political Geography vol.60, pp.100-109, 2017.

MEZA, M. Identidad minera y desarrollo sustentable, el caso de la cuenca del carbón en Chile. Sustentabilidad(es), no.5, pp.1-20, 2013. Recuperado de http://www.sustentabilidades.usach.cl/sites/sustentable/files/paginas/05-04.pdf Accesado en: 12 agosto 2018 . 
MIDNIGHT NOTES COLLECTIVE. Introduction to the new enclosures. Midnight Notes, 1990, Available at: http://www.midnightnotes.org/newenclos.html Accesssed in: 18 August 2018 .

NAVARRO CERRILLO, R., HAYAS, A., GARCÍA-FERRER, A., HERNÁNDEZ, R., DUHALDE, P., GONZÁLEZ, L. Caracterización de la situación pos-incendio en el área afectada por el incendio de 2005 en el Parque Nacional de Torres del Paine (Chile) a partir de imágenes multi-espectrales. Revista Chilena de Historia Natural, vol.81, no.1, pp.95-110, 2008. https://dx.doi.org/10.4067/S0716-078X2008000100008 Accesado en: 12 agosto 2018.

OJEDA LEAL, C.G. Valoración del Paisaje como Potencial Recurso de Desarrollo Sustentable. Estudio de Caso en el sur de Chile. Cidades, Comunidades e Territórios, vol.28, no.1, pp.33-55, 2014. Recuperado de: www.cidades.dinamiacet.iscte-iul.pt Accesado en: 12 agosto 2018 .

OSTROM, E. Governing the Commons: The Evolution of Institutions for Collective Action. Nat. Resources J., no. 2, pp.415-417, 1992. Available at: https://digitalrepository.unm.edu/nrj/vol32/iss2/6 Accesssed in: 02 December 2019.

PAUCHARD, A., AGUAYO, M., PEÑA, E., URRUTIA, R. Multiple effects of urbanization on the biodiversity of developing countries: the case of a fast-growing metropolitan area (Concepción, Chile). Biological Conservation, vol.127, no.3, pp.272-281, 2006. http://dx.doi.org/10.1016/j.biocon.2005.05.015 Accedido en 02 dic. 2019

PÉREZ, L., SALINAS, E. Crecimiento urbano y globalización: transformaciones del Área Metropolitana de Concepción, Chile, 1992-2002. Scripta Nova. Revista electrónica de Geografía y Ciencias Sociales, no.11, pp.251, 2007. Disponible en:

https://www.researchgate.net/profile/Leonel_PerezBustamante/publication/28184536_Crecimiento_urbano_y_globalizacion_transformaciones del_Area_Metropolitana_de_Concepcion_Chile_1992-

2002/links/5b4ad892a6fdccadaecb9df8/Crecimiento-urbano-y-globalizaciontransformaciones-del-Area-Metropolitana-de-Concepcion-Chile-1992-2002.pdf Accesado en: 12 agosto 2018.

PRADHAN, B. GIScience Tools for Climate Change Related Natural Hazards and Modelling. In: SINGH, P.J. (Ed.) Geoinformatics for Climate Change Studies. New Delhi: The Energy and Resources Institute (TERI), 2011, pp. 337-392.

RAMIS, A. El concepto de bienes comunes en la obra de Elinor Ostrom. Ecología Política, pp. 116-121, 2013. Disponible en: https:/www.ecologiapolitica.info/novaweb2/wpcontent/uploads/2015/12/045_Ramis_2013.pdf Accedido en 02 dic. 2019

ROJAS, J., AZÓCAR, G., MUÑOZ, M., VEGA, C., KINDLER, A., KABISH, S. Atlas social y ambiental del Área Metropolitana de Concepción Región del Biobio Chile. Transformaciones sociodemográficas y ambientales 1992-2002. Concepción: Universidad de Concepción, 2006. 
ROJAS, C., SEPÚlVEDA, E., BARBOSA, O., ROJAS, O., MARTÍNEZ, C. Patrones de urbanización en la biodiversidad de humedales urbanos en Concepción metropolitano. Revista de Geografia Norte Grande, no.61, pp.181-204, 2015. https://dx.doi.org/10.4067/S0718-34022015000200010 Accesado en: 12 agosto 2018.

ROJAS, C., PINO, J., JAQUE, E. Strategic environmental assessment in Latin America: A methodological proposal for urban planning in the Metropolitan Area of Concepción (Chile). Land Use Policy, vol.30, no.1, pp.519-527, 2013 https://doi.org/10.1016/j.landusepol.2012.04.018 Accesssed in: 18 August 2018.

ROJAS, C., MUNIZAGA, J., ROJAS, O., MARTÍNEZ, C., PINO, J. Urban development versus wetland loss in a coastal Latin American city: Lessons for sustainable land use planning. Land Use Policy no.80, pp.47-56, 2019 https://doi.org/10.1016/j.landusepol.2018.09.036 Accesssed in: 12 August 2018.

QUIROGA DÍAZ, N., GAGO, V. Los comunes en femenino. Cuerpo y poder ante la expropiación de las economías para la vida. Economía y Sociedad, vol.19, no.45, pp.1-18, 2014. https://doi.org/10.15359/eys.19-45.1 Accedido en 02 dic. 2019

SEPÚLVEDA, E., PARRA, L., BENÍTEZ, H., ROJAS C. Estados de naturalidad y heterogeneidad vegetacional de humedales palustres y su efecto sobre la diversidad de Macrolepidoptera (Insecta: Lepidoptera). SHILAP Revista Lepidoptera, vol.40, no.158, pp.155-170, 2012.

SMITH GUERRA, P., ROMERO ARAVENA, H. Efectos del crecimiento urbano del Área Metropolitana de Concepción sobre los humedales de Rocuant-Andalién, Los Batros y Lenga. Revista de Geografia Norte Grande, no. 43, pp.81-93, 2009. http://dx.doi.org/10.4067/S0718-34022009000200005 Accesado en: 12 agosto 2018.

SMITH, N. Uneven development: Nature, capital and the production of space. Georgia, USA: University of Georgia Press, 2008.

SOY CONCEPCIÓN. “Intentan proteger por ley al humedal Boca Maule en Coronel.” 22 de octubre de 2011. Disponible en: soychile.cl https://www.soychile.cl/Concepcion/Sociedad/2011/10/22/46433/Intentan-proteger-por-leyal-humedal-Boca-Maule-en-Coronel.aspx Accesado en: 12 agosto 2018.

STAMM, C., ALISTE, E. El aporte de un enfoque territorial al estudio de los conflictos socio-ambientales. F@ro: revista teórica del Departamento de Ciencias de la Comunicación, vol. 2, no. 20, pp. 66-78, 2014. Disponible en:

https://dialnet.unirioja.es/servlet/articulo?codigo=4926084 Accedido en 02 dic. 2019.

SUAZO, B., JAQUE, E., ROJAS, C., UTZ, R. Assessment of sustainability in urban planning of a coastal city: the city of Coronel, Southern Chile. En: BREBBIA, C. et al. (Eds.) Sustainable Development and Planning IV. Southampton: WIT Press, 2009, Vol. 2, pp. 665678. 
SVENDSEN, E., CAMPBELL, L.K. Urban ecological stewardship: Understanding the structure, function and network of community-based urban land management. Cities and the Environment (CATE), vol.1, no.1, pp.4-10, 2008

SWYNGEDOUW, E. Power, nature, and the city. The conquest of water and the political ecology of urbanization in Guayaquil, Ecuador: 1880-1990. Environment and planning A, vol.29, no. 2, pp. 311-332, 1997. https://doi.org/10.1068/a290311 Accesssed in: 18 August 2018 .

SWYNGEDOUW, E. Depoliticized environments: The end of nature, climate change and the post-political condition. Royal Institute of Philosophy Supplements, no. 69, pp.253-274, 2011.

TALLEDOS SANCHEZ, É. David Harvey, Ciudades rebeldes. Del derecho de la ciudad a la revolución urbana. Estudios Sociológicos, vol. 33, no. 99, pp. 688-693, 2015. Disponible en: http://www.scielo.org.mx/scielo.php?script=sci_arttext\&pid=S244864422015000300688\&lng=es\&nrm=iso Accedido en 02 dic. 2019.

THER RIOS, F. Complejidad territorial y sustentabilidad: Notas para una epistemológia de los estudios territoriales. Horizontes Antropológicos, vol. 12, n. 25, pp. 105-115, 2006. http://dx.doi.org/10.1590/S0104-71832006000100006. Accedido en 02 dic. 2019.

TORRES, R., AZÓCAR, G., ROJAS, J., MONTECINOS, A., PAREDES, P. Vulnerability and resistence to neoliberal environmental changes: An assessment of agriculture and forestry in the Biobío region of Chile (1974-2014). Geoforum, no.10, pp.107-122, 2015. http://dx.doi.org/10.106/j.geoforum.2014.12.013 Accesssed in: 12 August 2018.

UNU/IAS. Report on Urban ecosystems analysis identifying tools and methods, Genève: UNU, 2003. Retrieved from:

http://collections.unu.edu/eserv/UNU:3110/UNUIAS_Urban_Report2_1.pdf Accesssed in: 12 August 2018.

VÁSQUEZ, A., RIVEROS, S., ROMERO, H. Sustentabilidad del desarrollo urbano del Gran Concepción. Ponencia presentada en el XXVI Congreso Nacional y XVI Congreso Internacional de Geografía. Santiago, 2005

VILLAGRÁN, R., AGUAYO, M., PARRA, L., GONZÁLEZ, A. Relación entre características del hábitat y estructura del ensamble de insectos en humedales palustres urbanos del centro - sur de Chile. Revista Chilena de Historia Natural, vol.79, no.2, pp.195211, 2006. http://dx.doi.org/10.4067/S0716-078X2006000200006 Accesado en: 12 agosto 2018 .

WALTER, M. Conflictos ambientales, socio ambientales, ecológico distributivos, de contenido ambiental... Reflexionando sobre enfoques y definiciones. Boletín Ecos, no.6, pp.1-9, 2009. Disponible en:

http://www.crana.org/themed/crana/files/docs/252/180/2009_conflictos_ambientales_enfoqu es_definiciones.pdf Accesado en: 12 agosto 2018. 
WITTFOGEL, K. Oriental Despotism: A Comparative Study of Total Power. New York: Random House, 1957.

ŽIŽEK, S. First as tragedy, then as farce. London: Verso, 2009.

Agradecimientos: Esta investigación fue financiada por el proyecto FONDECYT 1171065 (EJC). CO agradece a la Beca de Doctorado Nacional ANID folio 21200455. Las autoras agradecen los aportes en cartografía a César Muñoz Barria. Asimismo, agradecemos los comentarios de las o los revisores anónimos.

\section{Edilia Jaque Castillo \\ Doctora en Ciencias Ambientales UDEC, Chile; graduada como profesora de Historia y Geografía de la Universidad de Concepción. Actualmente es Profesora Titular del Departamento de Geografía de la Universidad de Concepción. Profesora del Programa de Magister en Análisis Geográfico y del Magister en Ciencias Regionales. \\ Edmundo Larenas s/n, Barrio Universitario, Concepción-Chile. Teléfono: +56-41- 2204748 \\ Email: edjaque@udec.cl.https://orcid.org/0000-0002-6081-4204}

\section{Carolina Ojeda Leal}

Magíster en Desarrollo Regional y Medio Ambiente de la Universidad de Valparaíso y graduada como profesora de Historia y Geografía de la Universidad de Concepción. Actualmente es estudiante del Programa Doctorado en Arquitectura y Estudios Urbanos, Pontificia Universidad Católica de Chile. También es Profesora part time del Departamento de Historia y Geografía, Facultad de Comunicación, Historia y Cs. Sociales, Universidad Católica de la Santísima Concepción.

Lo Contador 1970, Providencia- Chile. Teléfono: +56-22-3547702 / Alonso de Ribera 2850 - Concepción - Chile. Teléfono: $+56-41-2345480$

Email: ccojeda@uc.cl https://orcid.org/0000-0002-9830-9203

\section{Darío Almendra C.}

Estudiante del Programa de Magíster en Análisis Geográfico de Universidad de Concepción y es Geógrafo de la misma universidad. Actualmente trabaja como geógrafo en la SEREMI de Salud de la región del Biobío.

O’Higgins 241, Concepción-Chile. Teléfono: +56-041-2726100

Email: dalmendra@udec.cl 